Technological University Dublin

DƯBLIN

ARROW@TU Dublin

2010-01-01

\title{
Postharvest Hardness and Color Evolution of White Button Mushrooms (Agaricus bisporus).
}

Debabandya Mohapatra

University College Cork, debabandya@gmail.com

Zuberi M. Bira

University College Cork

Joseph Kerry

University College Cork, joe.kerry@ucc.ie

See next page for additional authors

Follow this and additional works at: https://arrow.tudublin.ie/schfsehart

Part of the Food Processing Commons

\section{Recommended Citation}

Mohapatra, D. et al. (2010) Postharvest Hardness and Color Evolution of White ButtonMushrooms (Agaricus bisporus). Journal of Food Science, 75(3) E146-E152 doi: 10.1111/j.1750-3841.2010.01518.x.

This Article is brought to you for free and open access by the School of Food Science and Environmental Health at ARROW@TU Dublin. It has been accepted for inclusion in Articles by an authorized administrator of ARROW@TU

Dublin. For more information, please contact

arrow.admin@tudublin.ie, aisling.coyne@tudublin.ie, gerard.connolly@tudublin.ie.

Funder: This material is based upon works supported by the Science Foundation Ireland under Grant No. 04/BR/ E0073.

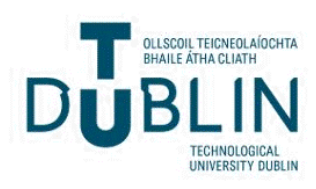




\section{Authors}

Debabandya Mohapatra, Zuberi M. Bira, Joseph Kerry, Jesus Maria Frias, and Fernanda A.R. Oliveira 
4 Debabandya Mohapatra ${ }^{1,4}$, Zuberi M. Bira ${ }^{2,5}$, Joe P. Kerry ${ }^{2}$, Jesus M. Frías $^{3}$ and Fernanda A.

$15{ }^{1}$ Process and Chemical Engineering Department, University College Cork, Cork City,

16 Ireland

$17 \quad{ }^{2}$ Food and Nutritional Sciences Department, University College Cork, Cork City, Ireland

$18{ }^{3}$ School of Food Science and Environmental Health, Dublin Institute of Technology, Cathal

19 Brugha Street, Dublin 1, Ireland

$20{ }^{4}$ Current Address: Faculty of Food Processing Technology and Bio-energy, Anand

21 Agricultural University, Anand, Gujarat, India

$22{ }^{5}$ Current Address: Agricultural Research institute, Ilonga, Kilosa, Morogoro, Tanzania 


\section{Abstract:}

24 The quality evaluation of mushrooms was studied by storing fresh white button mushroom 25 (Agaricus bisporus) for 6-8 days, at various controlled temperature conditions $\left(3.5-15^{\circ} \mathrm{C}\right)$ 26 and measuring the instrumental textural hardness and color of the mushroom cap for different 27 product batches. A non linear mixed effect weibull model was used to describe mushroom cap texture and color kinetics during storage considering the batch variability into account.

29 Storage temperature was found to play a significant role in controlling texture and colour 30 degradation. On lowering storage temperature i) the extent of the final browning extent in the 31 mushroom after storage was reduced; and ii) the rate textural hardness losses was slowed 32 down. A linear dependence of the final browning index with temperature was found. An 33 Arrhenius type relationship was found to exist between the temperature of storage and 34 storage time with respect to textural hardness. The average batch energy of activation was 35 calculated to be $207 \pm 42 \mathrm{~kJ} / \mathrm{mol}$ in a temperature range of $3.5-20^{\circ} \mathrm{C}$.

\section{Practical application}

37 This article evaluates how temperature abuse affects mushroom texture and colour, applying methods that allow for the consideration of the natural product variability that is inherent in mushrooms. Its result apply to mushroom producers, retail distribution and supermarkets for effective storage management. 


\section{Introduction:}

43 Mushroom marketers often face difficulties in choosing a safe storage conditions on receiving different batches of mushrooms. Mushrooms may vary in their harvesting date and time, cultivated mushroom variety, harvest batches, storage conditions adopted and cold chain regime followed (Hertog and others 2007a; Aguirre and others 2008). Post-harvest, mushrooms immediately start to soften and begin to brown in color due to enzymatic breakdown of plant cells and loss of moisture through respiration (Burton and others 1987, Jolivet and others 1998, Brennan and others 2000; Zivanovic and others 2003; Zivanovic and others 2004; Lespinard and others 2009). This results in reduced product acceptability, as consumer's preference and demand is for white, unblemished and hard textured mushrooms. Additionally, bruising and storage at elevated temperatures enhances the degradation process and reduces mushroom shelf-life (Burton, 1986). Consequently, monitoring cold-chain storage conditions that will preserve the quality of mushrooms is both critical and challenging (Aguirre and others, 2009)

Quality control during postharvest requires precise methodologies to estimate the acceptability of fresh produce of varying batches, growers, cultivation practices and post harvest treatments. In an ideal situation, all products should arrive with the same homogeneity as if it was from an experimental station unit, however, food retailers face an input of produce arising from different growers, possibly harvested on different dates and

61 locations and using very different cultural practices. Taken together, this has a significant 62 effect on the homogeneity of the product and its' time to reach the limit of marketability 63 (Hertog and others 2007b; Schouten and others 2004). Moreover, there is biological variation contributed by micro nutrients, growing conditions, etc. for each batch of produce. Different units of an individual batch may behave differently, even when stored under similar storage conditions (Brennan and others 2000; Hertog and others 2007a). 
Modeling the quality kinetics of fresh products attempts to better understand the fate of quality during storage, taking not only the primary modeling variable (time) into account, but more importantly, the secondary variables that may be controlled during storage to optimally maintain the quality attributes of the product. Such information would be helpful to both producers and sellers in enabling them to optimize product storage conditions and in identifying the significant factors affecting product shelf-life. Modeling may also reveal the ways in which variability affects the quality during operating storage conditions, which may in turn be used to define limits beyond which the quality of product may be compromised within a certain tolerance (Lavelli and others 2006).

An assessment of fresh produce shelf-life requires proper understanding of the two phenomena affecting the process i) biological metabolism, and ii) underlying variability. Model building is employed to assess the shelf-life, normally based on experimental data that is generated through repetitive quality measurements, either by destructive or non-destructive methods carried out in real-situation or laboratory conditions. The repetitive measurements form a longitudinal data structure which is well correlated with the subject within a batch, but are independent of the intra batch variability (Lammertyn and others 2003). Least squares regression is commonly used to analyze the data by averaging repeated measurements. Although this statistical method is robust to build models within normal food experiments, it accumulates all the variation in one error term and does not allow for the estimation of the different possible sources of variation. While this is sufficient for use with many experiments, it may be more desirable to estimate other and different sources of variability. In particular, postharvest technology is a field where this approach might prove to be interesting from a number of different perspectives, such as; i) to be able to estimate the weight of different variability sources (within batch, between batches, between producers), which will help to make clearer purchasing decisions ii) to identify if variability can be reduced at any particular 
storage condition and iii) to evaluate through a scenario analysis if making an hypothetical optimization in the cold chain, this optimisation will actually result in an appreciable improvement of the shelf life taking account of product variability. Mixed-effects models may be useful for those cases where one has to deal with within-subject, as well as betweensubject variability, especially when having to deal with a biological commodity. A mixed effects model has two components i) fixed effect term, which deals with the trend components and ii) random effect term, which deals with subject specific intercepts and variance (Pinheiro and Bates, 2000). Moreover, it allows for the presence of missing data and can allow for time-varying or unbalanced designs with unequal numbers of subjects across experimental groups (Pinheiro and Bates 2000; Lammertyn and others 2003). Several studies have been undertaken to predict the quality kinetics of fresh produce using mixed effect models (Lammertyn and others 2003; Piagentini and others 2005; Latreille and others 2006; Schouten and others 2007; Aguirre et al. 2009). A mixed effect model that addresses a hierarchical level of variation has been employed by various researchers (Fonseca and others 2002; Montanez and others 2002; Ketelaere and others 2006). Mushrooms are known to have a very short shelf- life and susceptible to browning and moisture loss due to the enzymatic activity and lack of cell wall. The quality deterioration is even faster at higher storage temperature conditions, due to enhanced metabolic activity. Therefore modeling the quality deterioration with respect to storage conditions provides ample opportunity for the mushroom growers and marketers to modify the storage and handling conditions in order to have higher shelf-life, thus reducing the economic loss. In this study, attempts were made to model product instrumental texture and color characteristics in order to predict mushroom shelf-life under different temperature storage conditions, taking batch variation into consideration, using a non-linear mixed effect model. 


\subsection{Materials and methods:}

118 Closed cup Agaricus Bisporus button mushrooms (white, close, uniform, clear, fresh, L

119 value $=90 \pm 5, a=0.3 \pm 0.8, b=10 \pm 2$ ), sourced from the Ranairee mushroom farm (Macroom,

120 Ireland) and commonly destined for retail supermarket sales, were delivered to the laboratory

121 using a temperature monitored distribution chain $\left(6 \pm 2^{\circ} \mathrm{C}, 80 \pm 15 \% \mathrm{RH}\right)$ in $7 \mathrm{~kg}$ crates

122 without any individual packaging. Bruised and damaged samples were discarded and samples

123 for analysis were taken at random from each batch of crates. Half of the mushrooms from the

124 same batch were stored in temperature controlled cold rooms at different temperatures $(5,10$,

$\left.12515 \pm 0.6^{\circ} \mathrm{C}\right)$ and the corresponding relative humidity was monitored $(86 \pm 7 \%)$. The other half

126 of the sample was kept in a domestic refrigerator that reproduced the ideal storage

127 temperature during retail and distribution of $3-4^{\circ} \mathrm{C}\left(3.5 \pm 1.5^{\circ} \mathrm{C}, \mathrm{RH} 92 \pm 5 \%\right)$ and served as

128 the control sample to observe differences between ideal storage and the temperature used for 129 each individual batch tested. The temperature range of $3.5-15^{\circ} \mathrm{C}$ was chosen considering the 130 practical temperature distribution chain of mushrooms i.e. during post-harvest handling, 131 transportation and storage. Texture and color measurement were performed after the 132 mushrooms reached equilibrium temperature and every $24 \mathrm{hr}$ thereafter, until the end of the 133 storage experiment, which varied between 6-8 days, depending on storage temperature, 134 taking random samples from the lot. A total of 14 batches of experiments were performed, covering a period of 1 year of production.

\subsection{Instrumental texture measurement:}

138 Texture measurement is a complex measurement, especially in a highly variable and 139 anisotropic solid as mushrooms (McGarry and Burton 1994). Stored mushrooms were 140 removed from storage and held at room temperature for $0.5 \mathrm{hr}$ before performing textural 141 assays. All such experiments were carried out using a texture profile analyser (Texture Expert 
142 Exceed, Stable Microsystems, UK), with a $5 \mathrm{~kg}$ load cell following a modification of the

143 method proposed by Gonzalez-Fandos and others (2000). The crosshead speed of the spindle

144 for the pre-test, post-test and test speed were kept at $1 \mathrm{~mm} / \mathrm{min}$. Only the mushroom caps

145 were used for texture hardness measurements. In order to obtain a sample with the same

146 tissue orientation and dimensions, a cylindrical sample of $10 \mathrm{~mm}$ diameter was bored out

147 from the mushroom cap using a steel borer and cut to $10 \mathrm{~mm}$ length using a sharp knife and

148 was then compressed to $50 \%$ of the original height using a $35 \mathrm{~mm}$ aluminium cylindrical

149 probe so as to achieve compression of the mushroom sample. Product hardness was the

150 variable analyzed for each sample. Tests were performed on 5 replicate mushroom samples,

151 from each storage condition, on each storage day, during the whole course of the trial period,

152 accounting for over 700 measurements.

2.2 Color measurement:

155 The color of the mushroom cap was measured using a Minolta Chroma Meter (Model CR-

156 331, Minolta Camera Co., Osaka, Japan), using the Hunter Lab Color Scale. The color was

157 measured at three equidistant points on each mushroom cap using an aperture diameter of $1584 \mathrm{~mm}$. Five mushrooms were randomly selected from each batch per day for the color 159 measurement, accounting for over 2800 measurements of color. Mushroom color has been 160 commonly measured using the L value of the Hunter scale (Brennan and others 2000; Jolivet, 161 1998; Cliffe-Byrnes and O’Beirne 2007), however some studies have pointed to changes in 162 other parameters of the hunter scale $\left(a^{*}\right.$ and $\left.b^{*}\right)$ related to browning (Aguirre and others 163 2008; Vizhanyo and Felföldi, 2000; Burton, 1998). In order to capture this variation in a 164 single index that would be related to a turn towards brown colour, the Browning index (BI) 165 was calculated using the following expression (Maskan 2001; Bozkurt and Bayram 2006): 
$166 B I=100 \times\left(\frac{X-0.31}{0.17}\right)$, where $X=\frac{\left(a^{*}+1.75 L\right)}{\left(5.645 L+a^{*}-3.012 b^{*}\right)}, \mathrm{L}, \mathrm{a}^{*}, \mathrm{~b}^{*}$ values represent the

167 lightness, redness and greenness of the sample.

168

\section{$169 \quad$ 1.0 Mathematical modeling}

170 The mathematical model to predict mushroom shelf-life was carried out using the data generated from measurement of the textural hardness and color (as indicated by the browning index).

173 Model building was performed using the following procedure:

174 1. An ANOVA analysis of the quality parameters clearly showed that they were all affected 175 by temperature and storage time $(\mathrm{p}<0.05)$. The primary modeling of the data was then 176 performed using suitable mathematical models for individual temperatures and batch experiments. After a graphical, the first order model, the biexponential model, the logistic model and the weibull model were used as candidate models to describe the kinetics of texture and browning. The most appropriate model which gave maximum determination coefficient $\mathrm{R}^{2}$, a low standard error, lower Akaike's Information Criterion (AIC) and Bayesian Information Criterion (BIC) was chosen. The AIC and BIC are model discrimination criteria used for selection nonlinear models, which consider the goodness of fit of the model and the number of parameters employed. The smaller the value of the AIC and BIC the better a model performs (Pinheiro and Bates, 2000).

2. The secondary modeling of the data considered two components: i) dependence of the texture and browning primary model parameters was described following the equations proposed in section 3.3 below ii) batch variation would be expected to follow the hypothesis of Hertog and others (2007a) that each individual product and batch has perturbation at the initial state at which it is processed. Extra random effects were 
190 introduced following this and its addition tested using a log-likelihood ratio test. A

191 likelihood-ratio test is a statistical test for making a decision between two models where

192 the hypothesis is based on the value of the log-likelihood ratio of the two models

193 following a chi-square distribution (Bates and Watts, 1988). The log-likelihood ratio test

194 is a conservative test that will check for statistical significance of adding further nested

195 random effects to a model (Pinheiro and Bates, 2000). The test requires that the two

196 models must be nested, this is, that if one of the models can be transformed into the other

197 by fixing one parameter.

198 3. Finally prediction plots using the Best Linear Unbiased Prediction (BLUP), which depict

199 the model prediction of each individual experiment considering the random effects

200 assigned to it in the model (Pinheiro and Bates, 2000), were made to confirm the $201 \quad$ suitability of the candidate models.

202 4. An iterative procedure was used to find the best candidate secondary model that could describe, with a minimum set of parameters, that data that resulted from the

204 experimentation.

205

\subsection{Modeling texture}

206 The best candidate primary model to describe the texture and browning kinetics, in a similar

207 way as with Kong and others (2007).

208 The textural hardness of the mushrooms was described by the weibull model as follows:

$209 \quad H=B_{H}+\left(A_{H}-B_{H}\right) e^{-e^{l k_{H} \times t} \beta_{H}}$

210 Where, $H$ is the textural hardness of the mushroom cap, $A_{H}$, and $B_{H}$ are the initial and final

211 hardness of mushroom cap during storage, $t$ is the time of storage (day), $l k_{H}$ is the natural

$212 \operatorname{logarithm}$ of the rate constant of the reaction and $\beta_{H}$ is the dimensionless shape parameter.

213 The shape parameter accounts for upward concavity of the curve $\left(\beta_{H}<1\right)$, a linear curve $\left(\beta_{H}\right.$

$214=1)$ as in case of first order kinetics, and downward concavity $\left(\beta_{H}>1\right)$ (Pinheiro and Bates, 9 
217 The browning index of the mushroom caps was analyzed using a modified weibull model, to

218 force the rate constant parameter to be positive:

$219 \quad B I=A_{B I}+\left(B_{B I}-A_{B I}\right) e^{-e^{i k_{B I}} \times t^{\beta_{B I}}}$

220 Where, $B I$ is the browning index, $A_{B I}$ is the upper asymptotic value of the weibull curve, $B_{B I}$, is the initial value of the browning index, $t$ is the time of storage is days, $l k_{B I}$ is the log rate constant of the reaction, and $\beta_{B I}$ is the shape factor for browning index.

\subsection{Temperature dependence}

The temperature dependence of the rate constant was modeled following an Arrhenius

226 relationship

$227 \quad k=k_{r e f} e^{-\frac{E a}{R}\left(\frac{1}{T}-\frac{1}{T_{r}}\right)}$

228 Where $k_{\text {ref }}$ is the rate constant at the reference temperature $T_{\text {ref }}\left(5^{\circ} \mathrm{C}\right), \mathrm{E}_{\mathrm{a}}$ is the energy of 229 activation of the process and $\mathrm{R}$ is the universal gas constant $\left(8.314 \mathrm{~kJ} \mathrm{Mol}^{-1} \mathrm{~K}^{-1}\right)$. In this way

$230 \mathrm{k}_{\mathrm{ref}}$ and $\mathrm{E}_{\mathrm{a}}$ are easy to interpret parameters and allow for comparison of the temperature 231 dependence of this process with other quality factors (chemical or not).

232 The temperature dependence of the $A, B$ and $\beta$ parameter followed a polynomial relation:

$$
y=a+b \times T+c \times T^{2}
$$

234 Where $y$ is the parameter $A, B$ or $\beta$ and $a$ and $b$ and $\mathrm{c}$ are the intercept, linear and quadratic dependence of the parameter with temperature, respectively. Parameters statistically non-

236 significant $(\mathrm{p}>0.05)$ were dropped from the model building.

\section{$237 \quad 3.5$ Statistical analysis}

238 On the basis of the primary models generated, the secondary models were developed by 
including the random effect terms that addressed batch and individual variance effects on

240 quality evolution. The non-linear mixed modeling was performed using the nlme library

241 (Pinheiro and Bates, 2000) from the R 2.9.1 software (R Development Core Team 2007), for

242 textural hardness and browning index.

\section{$244 \quad 4.0$ Results and discussion}

\subsection{Textural hardness}

246 The textural hardness kinetics of button mushrooms stored at different temperatures is shown

247 (Figure 1). It was evident that the while cap hardness could be maintained with storage at

$2483.5^{\circ} \mathrm{C}$, higher temperatures produced a decline in textural hardness that was more pronounced

249 with the increase in storage temperature. If storage temperature was changed to $10{ }^{\circ} \mathrm{C}$, after 4 250 days the mushrooms would have a texture different $(\mathrm{p}<0.05)$ from the control at $3.5^{\circ} \mathrm{C}$ and if 251 changed at $15^{\circ} \mathrm{C}$ after the $2^{\text {nd }}$ day of storage.

252 The estimated fixed and random effect parameters of the final model are outlined in table 1

253 with $95 \%$ confidence intervals, all parameters being significant $(\mathrm{p}<0.05)$. Initial models were 254 built considering within-lot and within-batch variability similar to Mohapatra and others 255 2008. When performing individual fits in each batch, it was observed that the standard deviation of the estimated power terms was very low compared to the average $(2.2 \pm 0.2)$. In

257 this way, the random effect associated to the $\beta$ term was removed from the model.

258 As indicated in Figure 1, the kinetics, and therefore the rate constant, of texture decay was 259 found to be dependent on the storage temperature. In order to study this, an Ahrrenius plot 260 with the random effects associated to the $k$ parameter of a model without temperature 261 dependence was built (see Figure 2) which confirmed this dependence. From the slope of the

262 linear regression of Figure 2, energy of activation of $190 \pm 40 \mathrm{~kJ} / \mathrm{mol}$ could be estimated. This

263 value was used as an initial estimate for the one-step estimation of the model parameters. 
264 The activation energies at the $95 \%$ confidence level and the estimates of the initial and final 265 values of hardness and the power term for the final model are shown (Table 1). The 266 activation energy for the loss of mushroom hardness $\left(207 \pm 42 \mathrm{kJmol}^{-1}\right)$ value was well within 267 the range of other quality characteristics for other reported forms of stored vegetables 268 (Giannakourou and Taoukis 2003; Piagentini and others 2005). The estimated power term

$269(2.2>1)$ suggested that the kinetics had a downward concavity feature that made texture kinetics depart from conventional first order kinetics. The best fitted values for mushroom textural hardness when stored under different temperature-time for different batches of mushrooms are shown (Figure 3). It can be seen that the model describes the kinetics and the differences between abuse storage temperature and control. Despite the natural variability, mushrooms abused suffer a decrease in hardness that is apportioned to the temperature abuse and that the model built in the present study is able to reproduce.

The random effect terms in Table 1 suggest that the final value of the mushroom hardness at the end of storage $\left(\sigma_{B H}\right)$ did not vary much among batches, compared to the variation in initial textural hardness $\left(\sigma_{A-B H}\right)$, which is 5 times higher. The structure of the best model fit and the estimated parameters point to the interesting hypothesis that as a result of storage, the variation between batches of mushrooms will decrease. The variation of the reaction rate constant between batches showed a coefficient of variation of over the $30 \%$, (Table 1). This is characteristic of the high variability associated to fresh produce for retail in general and in particular of mushrooms (Aguirre and others 2009)

\subsection{Browning index}

287 The kinetics of the average browning index for different temperatures of storage is shown in 288 (Figure 4). From a graphical inspection similar conclusions can be drawn as with the texture 
289 in respect to the effect of temperature abuse during the storage of mushrooms can be 290 concluded, with time and temperature having a significant effect $(\mathrm{p}<0.05)$. Since the loss of

291 hardness and browning of mushrooms are governed by enzymatic activities, low temperature 292 storage would inactivate the enzymes thus slowing down the metabolic activities and other 293 biochemical process. Storage at $5^{\circ} \mathrm{C}$ after 5 days produces a browning index different from 294 control conditions and after 4 days at $10^{\circ} \mathrm{C}$. From comparing Figure 1 and Figure 4 variation 295 in color of mushrooms seems to be less pronounced than that of texture. This is in agreement with previous results found for enzymatic activity responsible of browning (Mohapatra and 297 others 2008).

299 The best fit model to the data is presented in Figure 5. There was an increasing trend in the 300 browning index with respect to storage days and storage temperature. The pattern does not 301 seem to follow first order kinetics, although many researchers have proposed a logistic 302 function, or a zero order function, to describe this color change in fruits and vegetables 303 during storage (Giannakourou and Taoukis 2002; Lukasse and Polderdijk 2003; Muskovics 304 and others 2006; Hertog and others 2007b). In this study, a steady increase in the color pattern was evident as storage time progressed. When the mushrooms were initially received/purchased, their color was predominantly white, but as the storage days progressed

307 the discoloration on the cap intensified due to both enzymatic reactions (Jolivet and others 308 1998; Mohapatra and others 2008). The enzymes responsible for browning react with the 309 substrate and the evolution of brown pigmentation occurs. When there is no more substrate 310 available over a longer storage time, the enzymatic reaction slows down and the formation of 311 browning pigments stops (Jolivet and others 1998). As no decline or reversal in browning 312 pigments occurs once formed, the weibull model is most suitable in describing browning 313 index kinetics or color kinetics in mushrooms. There was a difference in the kinetics of 
314 browning index at higher temperatures. The estimates of both fixed and random parameters

315 are listed (Table 2). The final candidate model indicates that when storage temperatures are

316 very low, there will be no change in the BI with time, however, as temperature increases the

317 final value of the BI at long storage times will be higher. From the structure of the model it

318 can be inferred that no significant increase of browning index would be found theoretically at

$319 \quad 0^{\circ} \mathrm{C}$ (through extrapolation). Therefore the best policy would be to employ the lowest

320 refrigeration temperature possible, where the least color variation would be found. This

321 points to the need of ensuring cold chains in mushrooms that ensure the lowest level of

322 browning by maintaining the lowest temperature (Aguirre and others 2009). In terms of

323 slowing down browning as no significant dependence of the rate constant $\left(1 \mathrm{k}_{\mathrm{BI}}\right)$ or the shape

324 parameter $\left(\beta_{H}\right)$ with temperature browning kinetics will proceed in the same way

325 independently of the temperature. This seems to be in disagreement with previous results

326 found for frozen mushrooms (Giannakourou and Taoukis, 2002). This is possibly due to the

327 biological processes associated to fresh products where possibly an enzyme expression

328 process is taking place due to the natural senescence of the mushroom (Mohapatra, 2008),

329 instead of the slower temperature controlled processes in frozen foods. However the

330 significant temperature effect found in the parameter $\boldsymbol{B}_{\boldsymbol{B} \boldsymbol{I}}-\boldsymbol{A}_{\boldsymbol{B} \boldsymbol{I}}$ indicates that the higher the

331 temperature the higher the final browning stage of the mushrooms will be. Previous studies

332 (Mohapatra and others 2008) have pointed to an earlier over expression of browning related

333 enzymes associated with temperature abuse, which would be in agreement with this result.

334 While the initial stages of browning might be controlled by the integrity of the mushroom

335 tissues, the integrated effect of an earlier induction of high activity of browning enzymes by

336 temperature abuse would create higher color formation over time. The random effect

337 components of the models represent the effect that the product variability have on the

338 uncertainty of both quality index. As such, the $\boldsymbol{B}_{\boldsymbol{B} \boldsymbol{I}}-\boldsymbol{A}_{\boldsymbol{B} \boldsymbol{I}}$ associated to browning is the 
339 parameter with a bigger variability $\left(70 \% \mathrm{CV}\right.$ at $\left.3.5^{\circ} \mathrm{C}\right)$ followed by the initial value of the $\mathrm{BI}$

$340 \boldsymbol{A}_{\boldsymbol{B I}}(30 \%)$, whereas for the texture the $\boldsymbol{l}_{\boldsymbol{H}}$ is the parameter most affected by product

341 variability $(30 \% \mathrm{CV})$. This means that the biggest uncertainty resides in controlling the final

342 browning stage of the mushrooms, and then the rate of hardness losses will present the

343 biggest variability. Because of this under the present temperature range, the optimization of

344 texture through temperature control might appear more manageable than the control of 345 browning. However, the policy for controlling browning is clear despite of variability, the 346 lower the temperature the lower the extent of the browning.

\section{$348 \quad 5.0$ Conclusion}

349 This study has demonstrated the ability to predict the quality of fresh mushrooms stored 350 under isothermal conditions, using models that take into account not only the instrumental error as a source of variance, but also components of variability arising from product variability. The temperature dependence of these qualities gives further insight into the ability to choose proper time-temperature management during storage. Storage under low temperature would delay the biological decay process associated to texture and would extend the shelf-life of the product. In the same way, lower temperature will produce lower levels of browning. The models built can be useful in predicting the quality attributes of fresh mushrooms under a temperature range of $3.5-15^{\circ} \mathrm{C}$, which is adopted by most conventional distribution chains and more specifically, during the commercial storage of mushrooms.

359 Browning seems to be the quality index most influenced by product variability, especially in 360 the final value at long storage times. However a strategy of minimising storage temperature warrants a minimum browning appearance.

\section{Acknowledgements}


364 This material is based upon works supported by the Science Foundation Ireland under Grant

365 No. 04/BR/E0073. Sincere thanks are due to the Renaniree Mushroom Farm for the supply of 366 mushrooms.

367 


\section{References}

369 Aguirre L, Frías JM, Barry-Ryan C, and Grogan H. 2008. Assessing the effect of product variability on the management of the quality of mushrooms (Agaricus bisporus). Postharvest Biol Technol 49:247-254.

372

Aguirre L, Frías JM, Barry-Ryan C and Grogan H. 2009. Modelling browning and brown spotting of mushrooms (Agaricus bisporus) stored in controlled environmental conditions using image analysis. J Food Eng 91(2):280-286.

Bates DM and Watts DG. 1988. Nonlinear regression analysis and its applications. Wiley Series in Probability and Statistics. Wiley Interscience, London, UK.

Beecher TM, Magan N and Burton, KS. 2001. Water potentials and soluble carbohydrate concentrations in tissues of freshly harvested and stored mushrooms (Agaricus bisporus). Postharvest Biol \& Tech 22(2):121-131.

Bozkurt H, Bayram M. 2006. Color and textural attributes of sucuk during ripening. Meat Sci 73(2): 344-50.

Brennan M, Le Port G, Gormley R. 2000. Post-harvest treatment with citric acid or hydrogen peroxide to extend the shelf life of fresh sliced mushrooms. Leben Wiseen Tech 33: 285-9.

Burton KS. 1986. Quality - investigations into mushroom browning. Mushroom J. 158:6870.

Burton KS. 1989. The quality and storage life of Agaricus bisporus. Mushroom Sci. 12:287293.

Burton KS, Frost, CE and Atkey, PT. 1987. Effect of vacuum cooling on mushroom browning. Int J of Food Sci \& Tech 22:599-606.

Cliffe-Byrnes V, O'Beirne D. 2007. Effects of gas atmosphere and temperature on the respiration rates of whole and sliced mushrooms (Agaricus bisporus)-implications 
394 Fonseca SC, Oliveira FAR, Frías JM, Brecth, JK. 2002. Application of mathematical modeling and computer simulation to the design of modified atmosphere packages accounting for product variability. Computational Techniques in Food Engineering, Chapter 5, Balsa-Canto E, Mora J, Banga JR, Onate E. (editors), p. 70-84.

Giannakourou MC, Taoukis PS. 2002. Systematic application of time temperature integrators as tools for control of frozen vegetable quality. J of Food Sci 67(6):2221-2228.

Giannakourou MC, Taoukis PS. 2003. Kinetic modeling of vitamin C loss in frozen green vegetables under variable storage conditions. Food Chem 83: 33-41.

Gonzalez-Fandos E, Giménez M, Olarte C, Sanz S and Simón 2000. Effect of packaging conditions on the growth of micro-organisms and the quality characteristics of fresh mushrooms (Agaricus bisporus) stored at inadequate temperatures. $\mathrm{J}$ of Appl Micr 89:624-632.

Hertog MLATM, Lammertyn J, Scheerlinck N, Nicolaï BM. 2007a.The impact of biological variation on postharvest behavior: the case of dynamic temperature conditions. Postharvest Biol Technol 43: 183-92.

Hertog MLATM, Scheerlinck N, Lammertyn J, Nicolaï BM. 2007b. The impact of biological variation on postharvest behavior of Belgian endive: the case of multiple stochastic variables. Postharvest Biol Technol 43: 78-88. Res 102: 1459-83.

414 Ketelaere BD, Stulens J, Lammertyn J, Cuong NV, Baerdemaeker JD. 2006. A methodological approach for the identification and quantification of sources of biological variance in postharvest research. Postharvest Biol Technol 39: 1-9.

417 Kong F, Tang J, Rasco B, Crapo C. 2007. Kinetics of salmon quality changes during thermal 

processing. J Food Eng 83: 510-20.

419 Lammertyn J, De Ketelaere B, Marquenie D, Molenberghs G, Nicola1 BM. 2003. Mixed models for multicategorical repeated response: modeling the time effect of physical treatments on strawberry sepal quality. Postharvest Biol Technol 30: 195-/207.

Latreille J, Mauger E, Ambroisine L, Tenenhaus M, Vincent M, Navarro S, Guinot C. 2006. Measurement of the reliability of sensory panel performances. Food Qual Pref 17: $369-75$.

Lavelli V, Pagliarini E, Ambrosoli R, Minati JL, Zanoni B. 2006. Physicochemical, microbial, and sensory parameters as indices to evaluate the quality of minimallyprocessed carrots. Postharvest Biol Technol 40: 34-40.

Lespinard AR, Goni SM, Salgado PR, Mascheroni RH. 2009. Experimental determination and modelling of size variation, heat transfer and quality indexes during mushroom blanching. J Food Eng 92:8-17.

Lukasse LJS, Polderdijk JJ. 2003. Predictive modeling of post-harvest quality evolution in perishables, applied to mushrooms. J Food Eng 59: 191-8.

Maskan M 2001 Kinetics of colour change of kiwi fruits during hot air and microwave drying. J of Food Eng 48: 169-75.

McGarry A and Burton KS. 1994. Mechanical properties of the mushroom, Agaricus bisporus. Mycol Res 98(2):241-5.

Mohapatra D, Frías JM, Oliveira FAR, Bira ZM, Kerry J. 2008. Development and validation of a model to predict enzymatic activity during storage of cultivated mushrooms (Agaricus bisporus) J. Food Eng 86:39-48.

Montanez JC, Frías, JM, Fonseca SC, Luna R, Fernandez P, Oliveira FAR. 2002. Mathematical modeling accounting for food product variability using mixed effects models. In the Proceedings of International Conference on Simulation in Food and 
444 Muskovics G, Felföldi J, Kovács E, Perlaki R, Kállay T. 2006. Changes in physical properties during fruit ripening of Hungarian sweet cherry (Prunus avium L.) cultivars. Postharvest Biol Technol 40: 56-63.

447 Piagentini AM, Mendez JC, Guemes DR, Pirovani ME. 2005. Modelling changes of sensory attributes for individual and mixed fresh-cut leafy vegetables. Postharvest Biol Technol 38: 202-12.

Pinheiro JC, Bates DM. 2000. Mixed-Effects Models in S and S-Plus. Springer-Verlag, New York.

R Development Core Team. 2007. R: a language and environment for statistical computing. R Foundation for Statistical Computing, Available from: http://www.R-project.org

Schouten RE, Huijben TPM, Tijskens LMM, Van Kooten O. 2007. Modeling quality 455 attributes of truss tomatoes: Linking color and firmness maturity. Postharvest Biol Technol 45: 298-306.

Schouten RE, Jongbloed G, Tijskens LMM, Van Kooten O. 2004. Batch variability and 458 cultivar keeping quality of cucumber. Postharvest Biol Technol 32: 299-310.

Vizhanyo, T., Felföldi, J., 2000. Enhancing colour differences in images of diseased 460 mushrooms. Comp Elec Agric 26, 187-198.

Zivanovic S, Buescher R and Kim SK 2003 Mushroom texture, cell wall composition, color, and ultrastructure as affected by $\mathrm{pH}$ and temperature. J of Food Sci 68(5):1860-1865

Zivanovic S and Buescher R 2004 Changes in mushroom texture and cell wall composition affected by thermal processing. J of Food Sci 69(1): SNQ44-49

465

466 


\section{List of abbreviations}

$468 \quad \sigma$

$469 \quad \sigma_{A-B H}$

$470 \quad \sigma_{A B I}$

$471 \sigma_{A B I-A B I}$

$472 \sigma_{B H}$

$473 \quad \beta_{B I}$

$474 \quad \beta_{H}$

$475 \sigma_{l k B I}$

$476 \quad \sigma_{l k H}$

477 a,b,c

$478 \quad A_{B I}$

$479 A_{H}$

$480 \quad$ AIC

$481 \quad B_{B I}$

$482 \quad B_{H}$

$483 \quad$ BI

484 BIC

485 BLUP

486 CV

$487 \quad E_{a}$

$488 \quad \mathrm{H}$

$489 \quad k$

$490 \quad \mathrm{k}_{\mathrm{ref}}$

$491 \quad l k_{B I}$
Standard deviation

Variation in the hardness value at the initial stage, $\mathrm{N}$

Variation in the browning index value at the final stage

Variation in the browning index value at the final stage

Variation in the hardness value at the final stage, $\mathrm{N}$

Dimensionless Shape factor for browning index.

Dimensionless shape parameter for hardness

Variation in the log rate constant of the weibull curve for browning index

Variation in the log rate constant of the weibull curve for hardness

Constants of polynomial equation

Upper asymptotic value of the weibull curve

Initial hardness of mushroom cap, $\mathrm{N}$

Akaike's Information Criterion

Initial value of the browning index

Final hardness of mushroom cap, N

Browning Index

Bayesian Information Criterion

Best linear unbiased prediction

Coefficient of Variation

Activation Energy of the process, $\mathrm{kJmol}^{-1}$

Textural hardness, $\mathrm{N}$

Rate constant for weibull distribution

Rate constant at the reference temperature

Log rate constant of the browning reaction 
$492 l k_{H}$

$493 \mathrm{p}$

$494 \quad \mathrm{R}$

$495 \quad R^{2}$

496 REML

$497 t$

$498 \mathrm{~T}_{\text {ref }}$

499
The rate constant of texture decay at the reference temperature

Probability

Universal gas constant, $8.314 \mathrm{~kJ} \mathrm{Mol}^{-1} \mathrm{~K}^{-1}$

Coefficient of determination

Restricted maximum likelihood

Storage duration (day)

Reference temperature (278K) 


\section{List of Figures}

501

502 Figure 1 Average textural hardness kinetics of mushrooms at different storage temperatures $15^{\circ} \mathrm{C}, \nabla 10^{\circ} \mathrm{C},+5^{\circ} \mathrm{C}$, o $3.5^{\circ} \mathrm{C}$ (control). Error bars represent $95 \%$ confidence intervals based on the t-distribution for each time/temperature combination.

505

506

Figure 2 Arrhenius plot of the individually fitted $\kappa$ parameter for each batch studied.

507

508

509

510

511

512

Figure 3 Typical textural hardness kinetics of mushrooms batches at different storage temperatures with their respective control and best linear unbiased predictors (BLUP) of the model described in Table 1 (a) $\diamond 15^{\circ} \mathrm{C}$ (observed), $15^{\circ} \mathrm{C}$ (BLUP),(b)o $10^{\circ} \mathrm{C}$ (observed), $-10^{\circ} \mathrm{C}$ (BLUP), (c) $\square 5^{\circ} \mathrm{C}$ (observed), $-5^{\circ} \mathrm{C}$ (BLUP), $\Delta 3.5^{\circ} \mathrm{C}\left(\right.$ observed), $---3.5^{\circ} \mathrm{C}$ (BLUP)

Figure 4 Average Browning Index kinetics of mushrooms at different storage temperatures $15^{\circ} \mathrm{C}, \nabla 10^{\circ} \mathrm{C},+5^{\circ} \mathrm{C}$, o $3.5^{\circ} \mathrm{C}$ (control). Error bars represent $95 \%$ Gaussian confidence

Figure 5 Typical browning index kinetics of mushrooms at different storage temperatures intervals based on the t-distribution for each time/temperature combination. fitted to weibull model (a) $\diamond 15^{\circ} \mathrm{C}$ (observed), $-15^{\circ} \mathrm{C}$ (predicted),(b)o $10^{\circ} \mathrm{C}$ (observed), - $10^{\circ} \mathrm{C}$ (predicted), (c) $\square 5^{\circ} \mathrm{C}$ (observed), - $5^{\circ} \mathrm{C}$ (predicted), $\Delta 3.5^{\circ} \mathrm{C}$ (observed), --$3.5^{\circ} \mathrm{C}$ (predicted). It can be seen that mushroom storage temperature has an effect on the average browning kinetics and how inherent mushroom variability influences the whole process. 


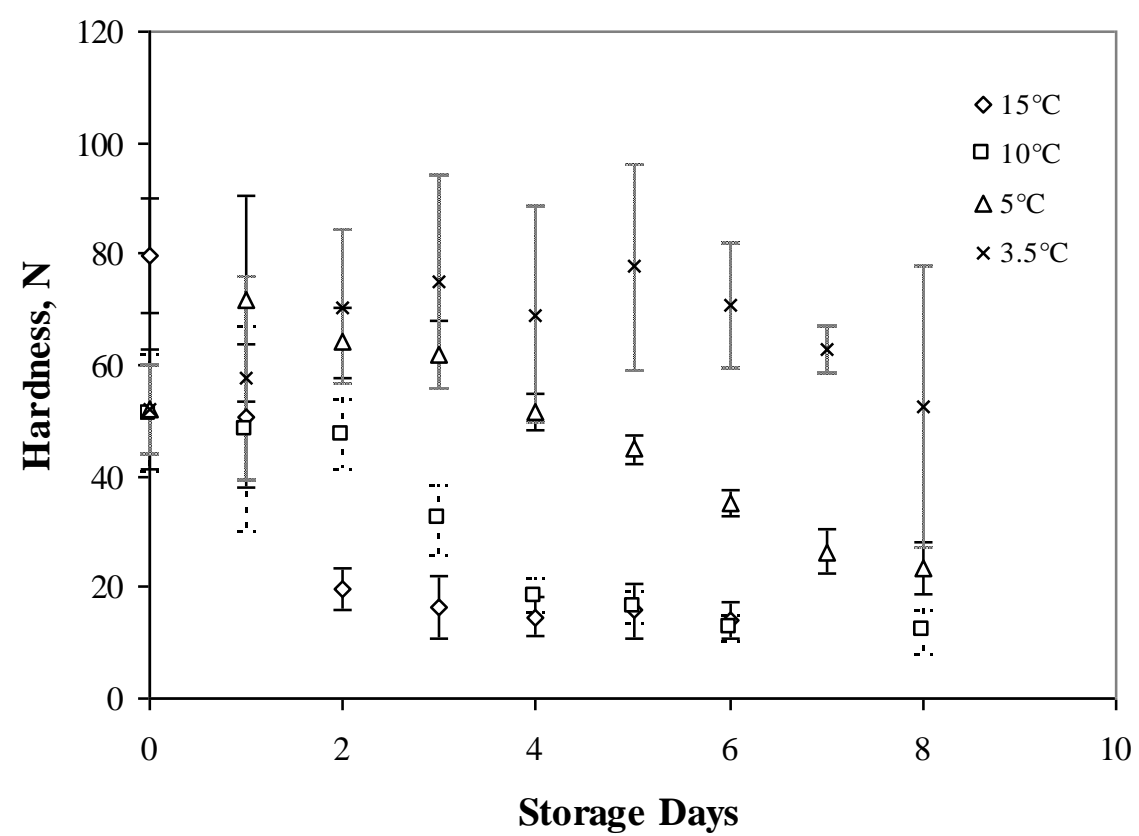

527

528 Figure 1 Typical textural hardness kinetics of mushrooms at different storage temperatures $\diamond$ $15^{\circ} \mathrm{C}$, o $10^{\circ} \mathrm{C}, \Delta 5^{\circ} \mathrm{C}, \times 3.5^{\circ} \mathrm{C}$ (control)

530 


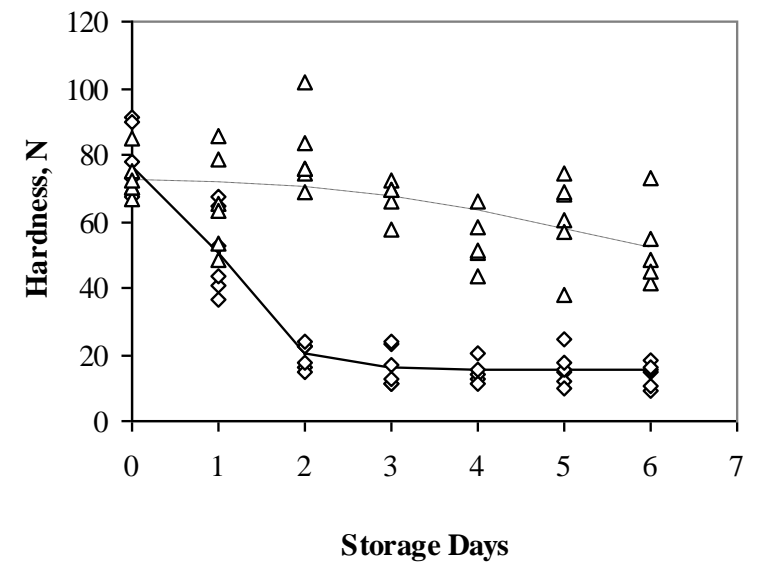

(a)

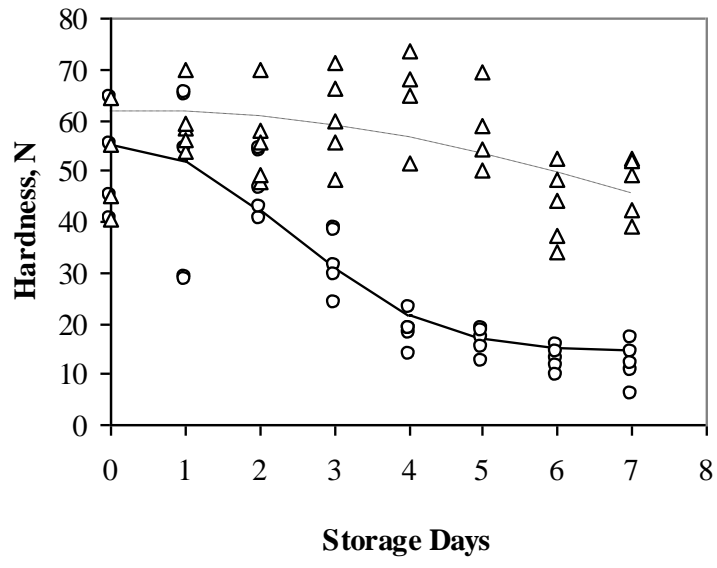

(b)

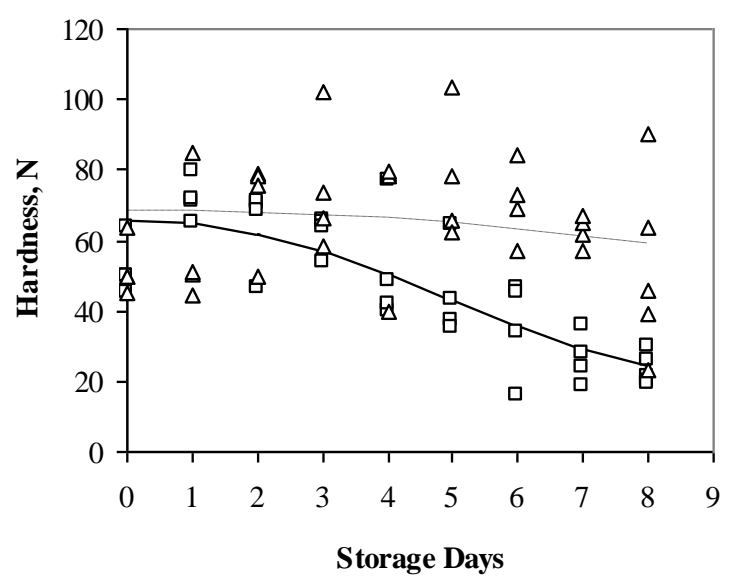

(c)

531

532

533

534

535

536

537
Figure 2 Typical textural hardness kinetics of mushrooms at different storage temperatures fitted to weibull model (a) $\diamond 15^{\circ} \mathrm{C}$ (observed), $-15^{\circ} \mathrm{C}$ (predicted),(b)o $10^{\circ} \mathrm{C}$ (observed), $-10^{\circ} \mathrm{C}$ (predicted), (c) $\square 5^{\circ} \mathrm{C}$ (observed), $-5^{\circ} \mathrm{C}$ (predicted), $\Delta$ $3.5^{\circ} \mathrm{C}($ observed $),---3.5^{\circ} \mathrm{C}$ (predicted) 


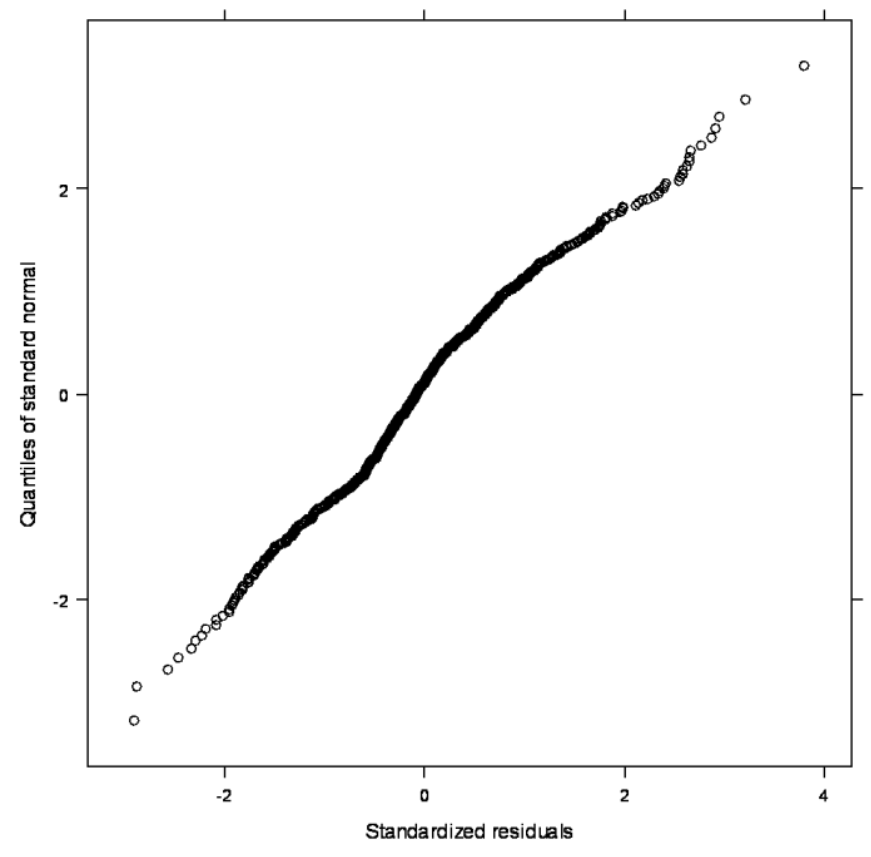

540

541 Figure 3 Normal distribution plot for the proposed weibull model fitted to the textural

542 hardness data of mushrooms stored under controlled conditions of temperature considering

543 the batch variability

544

545

546 


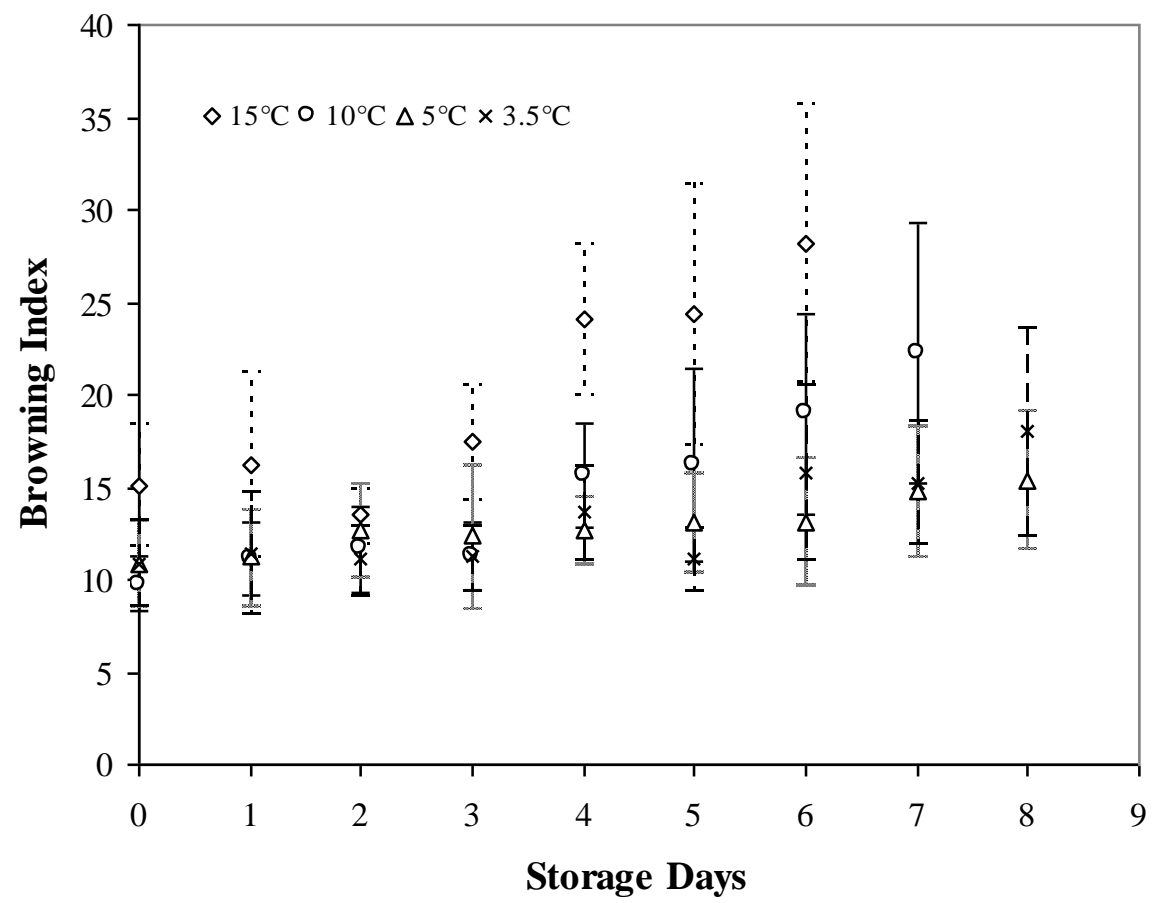

547

548 Figure 4 Typical browning index kinetics of mushrooms at different storage temperatures $\diamond$

$549 \quad 15^{\circ} \mathrm{C}, \mathrm{o} 10^{\circ} \mathrm{C}, \Delta 5^{\circ} \mathrm{C}, \times 3.5^{\circ} \mathrm{C}$ (control)

550 


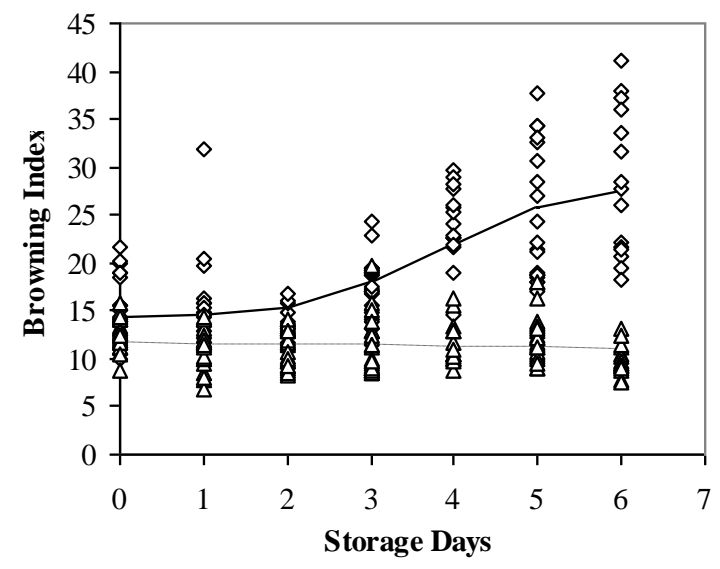

(a)

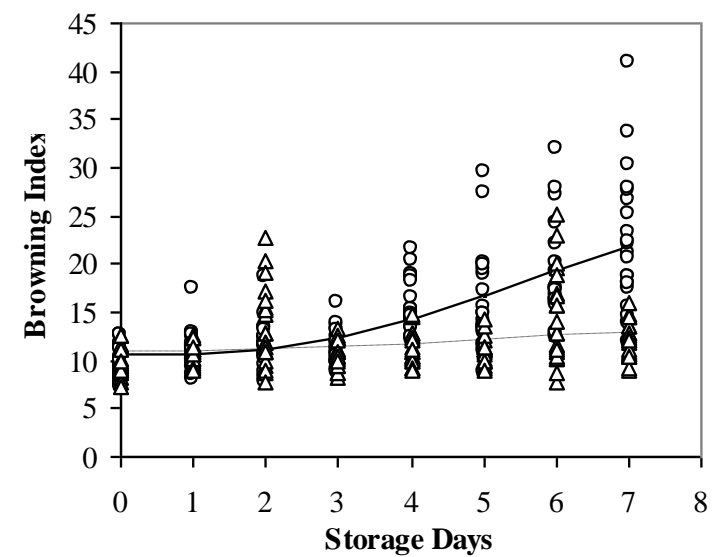

(b)

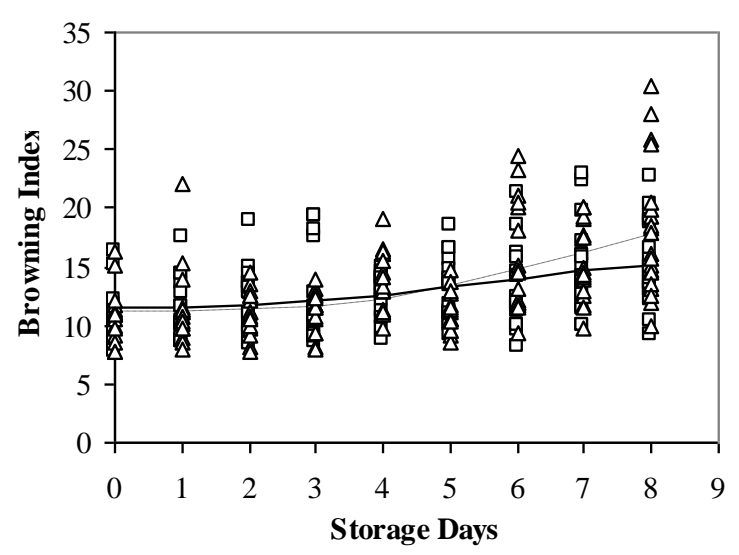

(c)

552

553

554

555

556

557
Figure 5 Typical browning index kinetics of mushrooms at different storage temperatures fitted to weibull model (a) $\diamond 15^{\circ} \mathrm{C}$ (observed), $-15^{\circ} \mathrm{C}$ (predicted),(b)o $10^{\circ} \mathrm{C}$ (observed), $-10^{\circ} \mathrm{C}$ (predicted), (c) $\square 5^{\circ} \mathrm{C}$ (observed), $-5^{\circ} \mathrm{C}$ (predicted), $\Delta$ $3.5^{\circ} \mathrm{C}$ (observed), --- $3.5^{\circ} \mathrm{C}$ (predicted) 
561

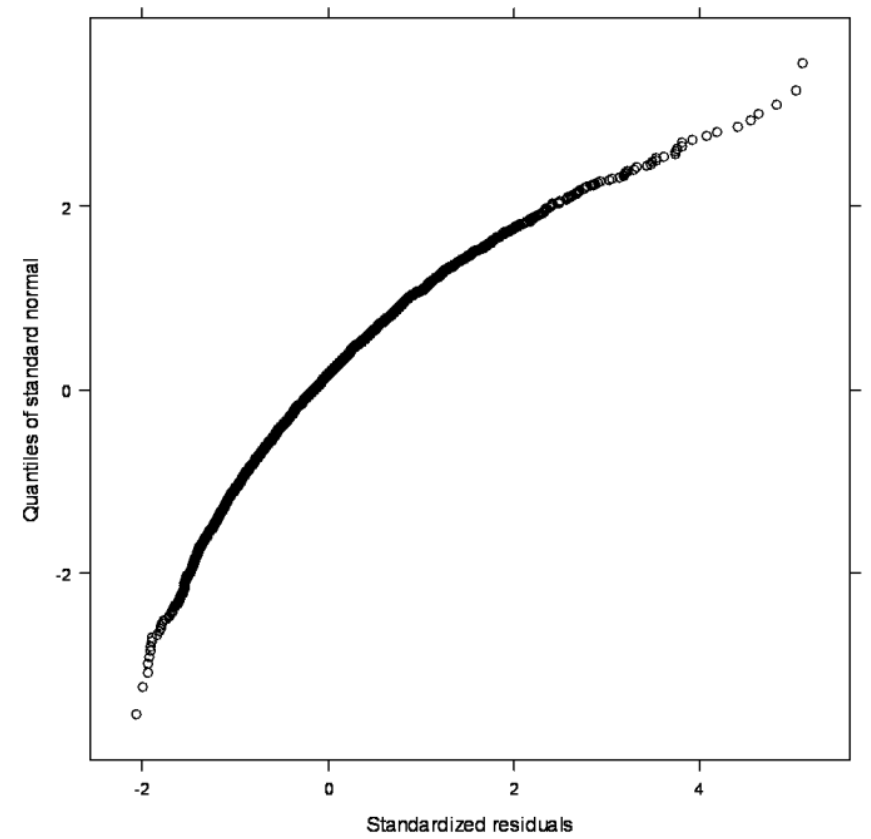

562

563 Figure 6 Normal distribution plot for the proposed weibull model fitted to the browning index

564 of mushrooms stored under controlled conditions of temperature considering the batch 565 variability

566 
567 Table 1 Parameter estimates of the Weibull model for predicting the textural hardness of 568 mushroom

\section{Fixed Parameters}

\begin{tabular}{llll}
\hline Parameter & Low 95\% CI & Estimate & Up95\%CI \\
$A$ & 13.241 & 15.726 & 18.211 \\
$A-B$ & -55.322 & -49.876 & -44.429 \\
$n$ & 1.840 & 2.234 & 2.628 \\
$\tau .($ Intercept $)$ & -1.443 & -0.263 & 0.917 \\
$\tau .[1 /$ Temperature $]$ & -179252.8 & -127525.4 & -75798.1 \\
Random parameters & & & \\
\hline Parameter & Low $95 \%$ CI & Estimate & Up95\%CI \\
\hline$\sigma(A)$ & 0.444 & 1.913 & 8.252 \\
$\sigma(A-B)$ & 6.945 & 10.250 & 15.126 \\
$\sigma(\tau[$ Intercept] $)$ & 0.830 & 1.207 & 1.755 \\
\hline$*$ shows the direct temperature effect on the rate constant of the hardness
\end{tabular}

570

571 
572 Table 2 Parameter estimates of the Weibull model for predicting the browning index of

573 mushroom

\section{Fixed Parameters}

\begin{tabular}{llll}
\hline Parameter & Low 95\% CI & Estimate & Up95\%CI \\
\hline Asymp & 17.542 & 21.470 & 25.397 \\
Initial & 11.462 & 12.184 & 12.905 \\
I $\tau$ & 1.307 & 1.540 & 1.772 \\
$\beta$ & 2.212 & 3.005 & 3.799 \\
\hline Random parameters & & & Up95\%CI \\
\hline Parameter & Low 95\% CI & Estimate & 11.842 \\
\hline$\sigma($ Asymp $)$ & 5.588 & 8.135 & 2.192 \\
$\sigma($ Initial $)$ & 1.082 & 1.540 & 0.615 \\
$\sigma($ I $\tau$ ) & 0.250 & 0.392 & 1.312 \\
$\beta$ & 0.668 & 0.936 &
\end{tabular}

574

575

576 